\title{
ЕЩЕ РАЗ ОБ ОБЪЕКТИВНОЙ ИСТИНЕ И АКТИВНОЙ РОЛИ СУДА В УГОЛОВНОМ ПРОЦЕССЕ
}

Аннотация: В связи с внесением в Государственную Думу проекта федерального закона «О внесении изменений в Уголовно-процессуальный кодекс Российской Федерации в связи с введением института установления объективной истины по уголовному делу», в пояснительной записке к которому говорится о традиционности для России требования об отыскании объективной истины в уголовном процессе, что закрепляется Уставом уголовного судопроизводства 1864 г., в статье проводится анализ текста Устава уголовного судопроизводства, объяснительной записки и комментариев к нему, а также ряда научных работ видных юристов того времени в целях выявления истинного отношения составителей Устава к принципу установления объективной истины, состязательности и активной роли суда в процессе. В ходе написания статьи были использованы стандартные методы юридического исследования: аналитический, историческо-правовой и сравнительно-правовой. На основании изучения вышеуказанных источников делается вывод о том, что уже в тот период рядом ведущих юристов разделялась позиция, согласно которой юридическое познание носит вероятностный характер, и выдвигалась концепция уголовно-судебной достоверности. В Уставе уголовного судопроизводства указание на необходимость достижения материальной истины противопоставлялось ранее существовавшему принципу достижения истины формальной, то есть необходимости доказывания виновности подсудимого любой ценой. Составители Уставов призывали к тщательному анализу судьей доказательств, представленных сторонами в состязательном процессе, по внутреннему убеждению. При этом осуждалась излишне активная роль председательствующего в судебном процессе по Уголовно-процессуальному кодексу Франции.

Ключевые слова: Устав уголовного судопроизводства, объективная истина, состязательность, равноправие сторон, презумпция невиновности, уголовный процесс, формальная оценка доказательств, внутреннее убеждение судьи, активная роль суда, судебный следователь.

DOI: 10.7256/1994-1471.2014.4.11193

Д искуссия о том, является ли установление объективной истины по делу целью уголовного процесса, возникла и развизадолго до того, как был принят новый Уголовно-процессуальный кодекс России, то есть еще в период, когда УПК РСФСР закреплял принцип установления объективной истины, и не прекратилась с принятием УПК РФ, когда указанный принцип был из него исключен. Новый толчок этой дискуссии был дан внесением 29 января 2014 г. в Государственную Думу проекта федерального закона № 440058-6 «0 внесении изменений в Уголовно-процессуальный кодекс Российской Федерации в связи с введением института установления объективной истины по уголовному делу». Автор законопроекта депутат А.А. Ремезков в своей пояснительной записке отмечает, что «ориентированность процесса доказывания по уголовному делу на достижение объективной истины является необходимым условием правильного разрешения уголовного дела и отправления справедливого правосудия» ${ }^{1}$. В поддержку данного тезиса он ссылается на романо-германскую модель уголовно-процессуального доказывания, «к которой традиционно тяготеет и российское уголовное судопроизводство» ${ }^{2}$, а также на то, что требования принять все меры к отысканию истины «традиционно содержались и в российском уголовно-процессуальном законодательстве, в частности в Уставе

\footnotetext{
Пояснительная записка к проекту федерального закона «О внесении изменений в Уголовно-процессуальный кодекс Российской Федерации в связи с введением института установления объективной истины по уголовному делу», С. 1.
}

Там же, С. 2.

(C) Шварц Ольга Альбертовна

* Кандидат юридических наук, консультант по правовым программам, Московский офис Всемирного банка

[olga_schwartz@mail.ru]

121069, Россия, г. Москва, ул. Большая Молчановка, д. 36/1. 
уголовного судопроизводства 1864 года...»³. В преддверие юбилея столь значительного памятника правовой культуры России как Устав уголовного судопроизводства 1864 года хотелось бы более тщательно разобраться в том, какие именно «традиционные» для России ценности там закреплены и на чем был основан сделанный составителями Уставов выбор в пользу введения тех или иных институтов.

Действительно, в статье 613 Устава уголовного судопроизводства содержалось императивное предписание судье, председательствующему в процессе, направлять разбирательство дела «к тому порядку, который наиболее способствует раскрытию истины» ${ }^{4}$. Объяснительная записка к проекту Устава уголовного судопроизводства также содержит следующие утверждения: «Начало судебного состязания сторон не исключает самодеятельности суда в уголовном судопроизводстве и не обязывает его решать дела по тем данным, которые предъявлены сторонами, но требует единственно того, чтобы по всем сведениям, относящимся к делу, сторонам предоставлена была возможность судебного состязания. Задача уголовного суда есть открытие в каждом деле безусловной истины. В стремлении к этой цели суд уголовный не может принимать в уважение желания сторон... Поэтому, если стороны не предъявили всех тех сведений, которые должны служить данными для основательного разрешения уголовного дела, то суд не может удовлетвориться одними их заявлениями, но обязан потребовать дополнительных сведений». ${ }^{5}$ В связи с этим небезынтересно, какой смысл придавал законодатель Российской Империи содержанию понятия «безусловная» или «материальная» истина и в каких условиях формировалось данное понятие.

Прежде всего, необходимо отметить, что принятие Устава уголовного судопроизводства 1864 г. стало результатом длительного исторического развития отечественного уголовного судопроизводства, и закрепленный им новый тип процесса не был революционной формой. Его следует рассматривать как эволюционный вариант того процесса, который сложился в России в период между изданием Свода законов и принятием Устава уголовного судопроизводства. И одним из естественных шагов на

\section{Там же, С. 2}

4 Цит. по тексту, размещенному на: http://constitution. garant.ru/history/act1600-1918/3137/

Объяснительная записка к проекту Устава уголовного судопроизводства, составленному комиссией, Высочайше учрежденною при государственной канцелярии для начертания проектов законоположений о преобразовании судебной части вообще - СПб., 1863. этом пути стала отмена теории формальной оценки доказательств.

В объяснительной записке к Судебным уставам говорилось, что от решения вопроса о том, как определяется сила доказательств, зависят и основные формы судопроизводства, и само устройство суда. До судебной реформы 1864 г. в Российской Империи господствовала так называемая формальная теория оценки доказательств, которая придавала больший или меньший вес определенным категориям доказательств, при этом наибольший вес был у признания обвиняемого, которое могло быть получено, в том числе, и под пытками. «Прежде собственное признание считалось единственным безусловным доказательством, и потому пытка была необходимым средством к вынуждению собственного признания в тех случаях, когда обвиняемый добровольно не сознавался» 6 . Объяснительная записка провозглашала, что теория доказательств, основанная единственно на их формальности, отменяется, а помещаемые в Уставе уголовного судопроизводства правила о силе судебных доказательств должны служить только руководством при определении виновности подсудимых по внутреннему убеждению судей, основанному на совокупности обстоятельств, обнаруженных при производстве следствия и суда. Таким образом, с принятием судебных уставов на смену чисто инквизиционному розыскному процессу приходит процесс смешанный, основанный на свободной оценке судом доказательств, рассмотренных в ходе гласного судебного разбирательства.

В результате реформы теория формальной оценки доказательств была отменена и ей на смену пришла другая - теория свободной оценки доказательств. Согласно ей задача суда состоит в поисках «материальной» (объективной) истины. Теперь решения и приговоры судов должны опираться на истинные факты, а не на домыслы. Для этого необходим «питательный разбор дел и всесторонний анализ всех имеющихся доказательств, без какого-либо вмешательства извне». Мерилом достоверности становится только внутреннее убеждение судей. Правила свободной оценки доказательств были призваны содействовать беспристрастности судей - было необходимо устанавливать в деле истину, а не доказывать вину подсудимого во что бы то ни стало. Именно в этом смысле (в противовес формальной

\footnotetext{
Судебные Уставы 20 ноября 1864 года с изложением рассуждений, на коих они основаны / В 5 выпусках. СПб.: Изд. Гос. канцелярии, 1866 - Выпуск 2. Устав уголовного судопроизводства, http://civil.consultant.ru/ reprint/books/118/ C. 10.
} 
истине) принцип отыскания материальной истины закреплялся Уставом. Как отмечал видный юрист того периода М.В. Духовской «... мы вправе сказать, что правильно организованный уголовный суд есть тот, который более в силах открыть правду, и притом правду не сухую, формальную, а жизненную, тот суд, который может лучше всего гарантировать свободу граждан, суд, равный для всех, гласный, отправляемый при участии народных представителей» ${ }^{7}$.

Следует заметить, что в указанный период многими западными и отечественными дореволюционными юристами уже разделялась позиция, согласно которой юридическое познание (в частности, о вине лица в совершении преступлений) носит вероятностный характер. Для дореволюционных авторов типично выдвижение концепции уголовно-судебной достоверности, судебной истины. «Надеяться вообще открыть всегда истину в уголовном процессе нельзя; все, чего можно достигнуть это так называемой уголовно-судебной достоверности» (М.В.Духовской) ${ }^{8}$. «Истина может быть познана до степени вероятности, а в определенных условиях - до степени полной достоверности» (И.Я.Фойницкий) ${ }^{9}$. «Уголовносудебная достоверность - стечение вероятностей, вытекающих из представленных на суде доказательств» (Вл. Случевский). ${ }^{10}$ Следовательно, невозможно утверждать, что авторы Устава уголовного судопроизводства действительно стремились призвать к установлению «обстоятельств уголовного дела такими, какими они были в действительности, то есть установления по делу объективной истины». ${ }^{11}$ Основной их целью было, скорее, желание переориентировать российское уголовное судопроизводство на более тщательный и взвешенный анализ доказательств, представленных сторонами в ходе открытого и гласного судебного разбирательства.

Духовской М. В. Русский уголовный процесс. Издание для студентов. - М., 1910-448 с.

8 Духовской, М.В.Понятие клеветы как преступления против чести частных лиц по русскому праву (по изданию 1873 года). - М.: Статут, 2004. - 409 с.

9 Фойницкий, И. Я. На досуге. Сборник юридических статей и исследований с 1870 г. Т. 2. (по изданию 1893 года) [Текст] / И. Я. Фойницкий. - М.: Статут, 2005. $411 \mathrm{c}$.

10 Случевский, В. К. О значении опытного, научного и философского знания в практике судьи (по изданию 1904 года). - М.: Статут, 2003. - 93 с.

11 Пояснительная записка к проекту федерального закона «О внесении изменений в Уголовно-процессуальный кодекс Российской Федерации в связи с введением института установления объективной истины по уголовному делу», С. 1.
Хотелось бы также остановиться на тезисе авторов внесенного в Государственную Думу законопроекта о «чуждой традиционному российскому уголовному процессу англо-американской доктрине» ${ }^{12}$ чистой состязательности и, видимо, более близкой ему активной роли суда в процессе.

Действительно, решив отойти от чисто розыскного, или, как выражались в тот период, «инквизиториального» процесса, составители Судебных уставов имели перед собой два варианта решения, выработанные к тому времени мировым опытом: англо-американский, в котором отсутствует предварительное следствие, суд сам ничего не выясняет, все делают стороны, а суд лишь следит за их поединком (чисто состязательный, или, в прежних формулировках, «обвинительный» процесс), и континентальный, где имеется письменное предварительное следствие, носящее розыскной характер, и суд (особенно во Франции) является активным участником судебного следствия (смешанный или «следственно-обвинительный» процесс). После тщательного исследования авторы Уставов избрали решение, более близкое к континентальному варианту, при этом за основу был взят Уголовно-процессуальный кодекс Франции 1808 г., однако данный выбор был, скорее, вынужденным.

В Записке Государственной Канцелярии об основных началах судоустройства и судопроизводства гражданского и уголовного, подготовленной в 1862 г., отмечается: «Не отвергая преимущества системы обвинительной, коей начала не были чужды нашему отечеству в самые отдаленные времена, II-ое Отделение находит однако же невозможным ввести эту систему внезапно, без предварительного к сему приготовления и в народе, и в правительственных установлениях» ${ }^{13}$. В комментариях к Уставу также указывается, что «... обсуждался вопрос о том, не следует ли заменить сию систему порядком обвинительным, действующим с большою пользою на западе Европы и даже в некоторых частях Российской Империи. Но введение такого порядка представлялось в то время невозможным, преимущественно по неудовлетворительности устройства наших судебных мест, вопрос о преобразовании которых тогда еще не был подвергнут ближайшему обсуждению» ${ }^{14}$. Таким образом, авторы Устава

\footnotetext{
12 Там же.

3 Записка Государственной Канцелярии об основных началах судоустройства и судопроизводства гражданского и уголовного. 1862. С. 118.

14 Судебные Уставы 20 ноября 1864 года с изложением рассуждений, на коих они основаны. - Выпуск 2. Устав уголовного судопроизводства, С. 1.
} 
считали состязательную модель процесса достаточно прогрессивной и не чуждой России, однако уровень развития соответствующих институтов, и прежде всего прокуратуры и адвокатуры, не позволял внедрить ее непосредственно. Более того, сама по себе французская модель, взятая российскими процессуалистами за образец, соединяла в себе розыскное предварительное расследование, опирающееся на ордонанс 1670 г., и состязательное судебное производство, построенное по английскому образцу. Как отмечал М.В. Духовской, «окончательно французский уголовный процесс по английскому типу кодифицирован был в царствие Наполеона I, в 1808 году» ${ }^{15}$. Отсюда можно сделать вывод о том, что именно состязательный процесс англо-саксонской модели, столь чуждый традиционным российским ценностям, по мнению авторов законопроекта, и был положен в основу уголовного судопроизводства авторами Судебных уставов. Более того, поиск истины не чужд и этому типу процесса решением по делу Техан против Соединенных Штатов (1966 г.) ${ }^{16}$ установление истины называется основной целью уголовного процесса, необходимость использования доказательств для целей установления истины и обеспечения справедливости судебного разбирательства закрепляется Правилом 102 Федеральных правил о доказательствах США.

Авторы Устава отлично понимали, что принцип состязательности в уголовном судопроизводстве имеет доминирующее значение, поскольку не просто определяет особую модель процесса, но и может рассматриваться в качестве критерия демократичности, цивилизованности и справедливости судопроизводства. Анализ многих положений рассматриваемого нормативного акта убедительно показывает, что состязательное начало играло в российском уголовном судопроизводстве исключительно важную роль, стороны представляли собой главную движущую силу производства по делу, особенно по делам, рассматриваемым мировым судьей. «Состязательное начало составляет душу современных как гражданских, так и уголовных процессов, - писал В.К. Случевский, - а потому мера развития в том и другом процессе состязательного или противополагающегося ему следственного начала есть вопрос политики права» ${ }^{17}$.

15 Духовской М. В. Русский уголовный процесс. Издание для студентов. - М., 1910.

16 Tehan v. United States ex. rel. Shott, 382 US. 406, 416 (1966).

17 Случевский В.К. Учебник русского уголовного процесса. Введение. Ч.1. Судоустройство. - М., 2008.
Состязательность, введенная судебными уставами в противоположность дореформенному инквизиционному судопроизводству, была важным демократическим институтом. В то же время и суд не занимал пассивного положения. Поэтому, подчеркивая значение состязательности, русский процессуалист Н.Н. Розин писал, что «состязательный принцип вполне совместим с инструкционным началом процесса, в силу которого последний, сохраняя за сторонами их процессуальные права, в то же время открывает для суда возможность активной деятельности и, таким образом, полного раскрытия истины в деле» ${ }^{18}$.

Однако, следует более тщательно рассмотреть пределы активности суда, заложенные в Уставе уголовного судопроизводства. Так, власти председателя принадлежали: направление хода дела в такой постепенности процессуальных действий, которая наиболее, по мнению его, способствует раскрытию истины (статьи 611, 613, 614 УУС) (при этом указывалось, что он обязан предоставить каждому подсудимому всевозможные средства к оправданию и не может устранить ни одного из подсудимых от предъявления замечаний как по существу всякого дела, так и относительно способа его производства на суде (статья 612 уус)); наблюдение за внешним порядком и благочинием в заседании, в частности предупреждение внешнего влияния на присяжных заседателей и недозволенных сношений посторонних лиц как с ними, так и со свидетелями (статьи 615-618 УУС); устранение всего, что не имеет прямого отношения к делу, в частности, оскорбительных для чьей-либо личности отзывов, нарушения должного уважения к религии, закону и установленным властям (статья 611 УУС). ${ }^{19}$ Согласно статье 630 УУС в представлении и исследовании доказательств стороны находились в равном положении и могли достаточно активно защищать свои интересы. Председательствующий принимал активное участие в судебном следствии наряду со сторонами, и по своему усмотрению, независимо от позиции сторон был вправе: вызвать прежних экспертов или назначить новую экспертизу (статьи 690, 692 УУС); оглашать протоколы осмотров, освидетельствований (статья 687 УУС); проводить новые осмотры (статья 688 УУС); допрашивать свидетелей и подсудимого. Нельзя сказать, что приведенный перечень так уж разительно отличается

\footnotetext{
18 Розин, Н. Н. Уголовное судопроизводство. - Петроград, 1914. - С. 497-498.

19 Цитируется по тексту, размещенному на: http:// constitution.garant.ru/history/act1600-1918/3137/
} 
от полномочий председательствующего по действующему УПК РФ.

При этом в комментарии к статьям 523-527 Устава отмечается: «Изыскание обстоятельств дела и собрание доказательств в обличение или оправдание обвиняемого несравненно удобнее производить на месте происшествия, заключающего в себе преступление, нежели в суде, который может находиться в дальнем расстоянии от того места. Коллегиальный состав суда может способствовать лишь зрелому обсуждению обстоятельств, а отнюдь не изысканию их, или так называемому розыску... Все это убеждает в том, что задача судебного следствия должна состоять только в поверке и разъяснении собранных при предварительном следствии доказательств и улик» ${ }^{20}$.

Далее, комментарий к статье 611 Устава четко описывает пределы полномочий председательствующего судьи: «Охранение внешнего порядка судопроизводства, направление допросов и прений на суде, предоставление подсудимому всех законных средств к оправданию, принятие мер против стачки допрашиваемых лиц, наблюдение, чтобы присяжные воспользовались всеми способами к обстоятельному рассмотрению дела, разъяснение им всего для них непонятного и ограждение их от опасности постановления решений под неблагоприятным для правосудия внешним влиянием - все это несомненно принадлежит единоличной власти председателя суда. Направляя ход дела к тому порядку, который наиболее способствует раскрытию истины, председатель может даже распорядиться, чтобы судебное следствие, в отношении к каждому из соучастников в одном и том же преступлении, производилось отдельно, с сохранением, однако, общей связи дела (ст. 613). Но далее этих пределов власть председателя суда не должна простираться» ${ }^{21}$.

Слишком активная роль суда во французском уголовном процессе подвергалась критике многими видными российскими юристами. Как отмечал М.В. Духовской: «Многие изменения, допущенные этим кодексом, заслуживали и заслуживают серьезных возражений. Таковы, в особенности, ... чрезмерное усиление прокуратуры и власти председательствующего...» ${ }^{22}$ Анализ приведенных выше полномочий председательствующего судьи по Уставу уголовного судопроизводства указывает на то, что он не

\footnotetext{
20 Судебные уставы 20 ноября 1864 года с изложением рассуждений, на коих они основаны. Выпуск 2, С. 202.

21 Судебные уставы 20 ноября 1864 года с изложением рассуждений, на коих они основаны. Выпуск 2, С. 222.

22 Духовской М. В. Русский уголовный процесс. Издание для студентов. - М., 1910.
}

обладал такой неограниченной властью, как президент французского суда, что позволяет говорить о большей реализации состязательных начал в судебном следствии российской модели. По Уставу уголовного судопроизводства состязательность являлась средством установления истины. «При том для судьи, долженствующего уразуметь дело до достижения внутреннего убеждения, недостаточно одного допроса подсудимого и свидетелей чрез следователя и простых ответов их, ему необходимы подробный разбор и категорическое разъяснение всего, что представляется по делу против и в пользу обвиняемого, а сие достигается лишь прениями обвинителя с защитником подсудимого» ${ }^{23}$.

Устав уголовного судопроизводства впервые провозгласил принцип презумпции невиновности. Статья 14 Устава закрепляет, что «Никто не может быть наказан за преступление или проступок, подлежащие судебному ведомству, иначе как по приговору надлежащего суда, вошедшему в законную силу ${ }^{24}$. В отличие от авторов законопроекта о введении объективной истины, называющих данный принцип «юридической фикцией», составители Судебных уставов высоко его оценивали: «Постановление это основано на соображении вошедших в свод 1857 года узаконений и принадлежит к числу важнейших, можно сказать коренных начал уголовного законодательства, принятых во всех новейших и лучших судопроизводствах иностранных» ${ }^{25}$. Статья 754 Устава устанавливает, что фундаментом обвинительного приговора является несомненность происшедшего события преступления и причастность к нему подсудимого. Сомнения толкуются в пользу обвиняемого - статья 769 гласит: «При разделении голосов на два или более мнения за основание решения принимается то из них, которое соединяет в себе наиболее голосов; при равенстве их отдается предпочтение мнению, принятому председателем суда, а если мнения разделились так, что голос председателя не может дать перевеса, то тому из равносильных по числу голосов мнений, которое снисходительнее к участи подсудимого» ${ }^{26}$.

И, вкратце, о предложении авторов законопроекта, связанном с «введением до-

23 Записка Государственной Канцелярии об основных началах судоустройства и судопроизводства гражданского и уголовного. 1862. С. 134.

24 Цит. по тексту, размещенному на: http://constitution. garant.ru/history/act1600-1918/3137/

25 Судебные уставы 20 ноября 1864 года с изложением рассуждений, на коих они основаны. Выпуск 2, С. 32.

26 Цит. по тексту, размещенному на: http://constitution. garant.ru/history/act1600-1918/3137/ 
полнительных требований в отношении должностных лиц, уполномоченных осуществлять от имени государства уголовное преследование» ${ }^{27}$. Согласно пояснительной записке «им предписывается сохранять объективность и беспристрастность, не допуская обвинительного уклона в доказывании. Кроме того, для этих лиц предусматривается обязанность тщательно и всесторонне исследовать и оценивать обстоятельства, оправдывающие обвиняемого (подозреваемого) или смягчающие его наказание, и оценивать их наравне с обстоятельствами, изобличающими обвиняемого (подозреваемого) или отягчающими его наказание» ${ }^{28}$. Действительно, в соответствии с Уставом уголовного судопроизводства 1864 г. следователь в ходе своей деятельности должен был сохранять объективность - статья 265 гласила: «При производстве следствия судебный следователь обязан с полным беспристрастием приводить в известность как обстоятельства, уличающие обвиняемого, так и обстоятельства, его оправдывающие». Однако ключевые слова здесь - судебный следователь. Как уже отмечалось выше, для целей отделения власти административной (обвинительной) от власти судебной и создания в России самостоятельного и независимого суда была заимствована континентальная система судопроизводства, причем ее французская модель, где следствие проводилось следственным судьей.

При разработке нового Устава уголовного судопроизводства, в связи с сохранением розыскного характера предварительного расследования, составители попытались придать данной стадии процесса характер судебной деятельности. При этом предварительное следствие поручалось судебному следователю, который имел должность служащего суда и находился в организационном и процессуальном подчинении окружного судьи. Именно за судом было закреплено право принятия основополагающих решений по делу, а при отсутствии фигуры защитника на предвари- тельном следствии, «судебные следователи, подобно следственному судье во Франции, соединяли в себе функции и судьи, и обвинителя, и защитника». ${ }^{29}$ Такое процессуальное положение судебного следователя объясняло необходимость для него сохранять объективность. В настоящее время, когда следователь выполняет функцию уголовного преследования, а состязательные начала процесса частично перенесены на стадию предварительного расследования (допуск защитника с момента задержания, ареста или предъявления обвинения; право защитника участвовать в проведении следственных действий, в которых участвует обвиняемый, проводить опросы и собирать материалы), уже невозможно говорить о сохранении следователем какой-либо объективности и беспристрастности.

В заключение хотелось бы еще раз подчеркнуть, что судебная реформа 1864 г. коренным образом изменила уголовное судопроизводство. Уставы 1864 г. заложили основу формирования новой исторической модели уголовного процесса, построенной на принципах гласности, устности, состязательности, равноправия сторон, презумпции невиновности. В недрах самодержавного строя зародились такие принципы и институты уголовной юстиции, которые позволили поставить во главу угла судебную власть, как самостоятельную и независимую ветвь государственной власти. Конечно же, составителям Уставов пришлось реформировать довольно архаичную судебную систему, и им не сразу удалось создать идеальную (тем более уж - «традиционную») модель уголовного процесса, однако произведенные преобразования были действительно передовыми, и не только для данного периода в истории нашей страны. До настоящего времени очень многие положения законодательства того периода являются актуальными, а его составителей можно назвать гораздо более прогрессивными, чем некоторых теперешних законодателей.

\section{Библиография}

1. Духовской, М. В. Русский уголовный процесс. Издание для студентов. - М., 1910 - 448 с.

2. Духовской, М. В. Понятие клеветы как преступления против чести частных лиц по русскому праву (по изданию 1873 года). - М.: Статут, 2004. - 409 с.

3. Фойницкий, И. Я. На досуге. Сборник юридических статей и исследований с 1870 г. Т. 2. (по изданию 1893 года). - М.: Статут, 2005. - 411 с.

27 Пояснительная записка к проекту федерального закона «О внесении изменений в Уголовно-процессуальный кодекс Российской Федерации в связи с введением института установления объективной истины по уголовному делу», С. 6.

28 Там же.

29 Случевский В.К. Учебник русского уголовного процесса. Введение. Ч.1. Судоустройство. - М., 2008. C.302. 
4. Случевский, В. К. О значении опытного, научного и философского знания в практике судьи (по изданию 1904 года). - М.: Статут, 2003. - 93 с.

5. Tehan V. United States ex. rel. Shott, 382 US. 406, 416 (1966).

6. Случевский, В.К. Учебник русского уголовного процесса. Введение. Ч.1. Судоустройство. - М., 2008.

7. Розин, Н. Н. Уголовное судопроизводство. - Петроград, 1914. - С. 497-498.

8. Случевский, В.К. Учебник русского уголовного процесса. Введение. Ч.1. Судоустройство. - М., 2008. - С. 302.

9. Юй Ишэн. Юридическая истина в определении сущности предмета доказывания // LEX RUSSICA. - 2014. - 1. - C. 58-66. DOI: 10.7256/1729-5920.2014.1.10286.

10. Прохоров М.М. Истина и действительность // Философские исследования. - 2013. - 6. C. 293-387. DOI: 10.7256/2306-0174.2013.6.333.

11. Жамборов, М.С. Конституционный принцип состязательности как способ аргументированного обоснования правовой позиции сторон в российском судопроизводстве // Актуальные проблемы российского права. - 2013. - 4. - С. 424-432.

\section{References}

1. Dukhovskoi, M. V. Russkii ugolovnyi protsess. Izdanie dlya studentov. - M., 1910-448 s.

2. Dukhovskoi, M. V. Ponyatie klevety kak prestupleniya protiv chesti chastnykh lits po russkomu pravu (po izdaniyu 1873 goda). - M.: Statut, 2004. - 409 s.

3. Foinitskii, I. Ya. Na dosuge. Sbornik yuridicheskikh statei i issledovanii s 1870 g. T. 2. (po izdaniyu 1893 goda). - M.: Statut, 2005. - 411 s.

4. Sluchevskii, V. K. O znachenii opytnogo, nauchnogo i filosofskogo znaniya v praktike sud'i (po izdaniyu 1904 goda). - M.: Statut, 2003. - 93 s.

5. Tehan V. United States ex. rel. Shott, 382 US. 406, 416 (1966).

6. Sluchevskii, V. K. Uchebnik russkogo ugolovnogo protsessa. Vvedenie. Ch.1. Sudoustroistvo. - M., 2008.

7. Rozin, N. N. Ugolovnoe sudoproizvodstvo. - Petrograd, 1914. - S. 497-498.

8. Sluchevskii, V.K. Uchebnik russkogo ugolovnogo protsessa. Vvedenie. Ch.1. Sudoustroistvo. - M., 2008. - S. 302.

9. Yui Ishen. Yuridicheskaya istina v opredelenii sushchnosti predmeta dokazyvaniya // LEX RUSSICA.2014. - 1. - C. 58-66. DOI: 10.7256/1729-5920.2014.1.10286.

10. Prokhorov, M.M. Istina i deistvitel'nost' // Filosofskie issledovaniya. - 2013. - 6. - C. 293-387. DOI: 10.7256/2306-0174.2013.6.333.

11. Zhamborov, M.S. Konstitutsionnyi printsip sostyazatel'nosti kak sposob argumentirovannogo obosnovaniya pravovoi pozitsii storon v rossiiskom sudoproizvodstve // Aktual'nye problemy rossiiskogo prava. - 2013. - 4. - C. 424-432.

Материал поступил в редакцию 27 февраля 2014 г. 